\title{
Density Functional Theoretical Study on the Hydricities of Transition Metal Hydride Complexes in Water
}

\author{
Suk-Bok Kang, Young Seuk Cho, and Sungu Hwang ${ }^{+*}$ \\ Department of Statistics, letmgnam Lninersity, Gleongsan 712-749, Korea \\ ${ }^{\dagger}$ Department of Statistics. Pusan National Liniversity, Busan 609-735, Korea \\ ${ }^{\dagger}$ Department of Nanomedical Engineering, Pusan Kational Lniversitw, Hirvang 627-706, Korea \\ ${ }^{*}$ E-mail: sunguiăpusan ac.kr \\ Received Julv 16, 2009, Accepted October 7, 2009
}

\begin{abstract}
The hydricities of $\mathrm{d}^{\circ}$ metal hydride complexes in aqueous solution were calculated by using density finctional theoretical (DFT) calculations coupled with a Poisson-Boltzmann (PB) solvent model. Hydricity describes the hydride donor ability of the metal-hydrogen bond, which assists in the study of the mechanism of many catalytic processes and chemical reactions that involve transition metal hydrides. The calculation scheme produced hydricity values that were in good agreement with experinental estimation. The inclusion of a water molecule as a weakly bound ligand to five-coordinate metal complexes gave an improved correlation result.
\end{abstract}

Key Words: DFT. Hỵdricity. Transition metal hỵdride complexes

\section{Introduction}

Hydricity is related to the thermodynamics of the heterolytic dissociation of the hydride anion from its parent molecule. ${ }^{\text {] It }}$ has been used in determining the reactivity and the mechanism of hydride shift reactions ${ }^{2}$ and hydride abstraction reactions. ${ }^{3}$ The reduction of carbon dioxide by transition metal hydride complexes is another good example to which the concept can be applied. ${ }^{4}$ Although the concept of hydricity parallels that of acidity. the experimental estimation of hydricity requires a series of chemical equations. unlike the case of acidity. ${ }^{1}$ Thus the accuracy of experimentally calculated values of hydricities may be affected by the errors accumulated from each of these steps. Therefore. it is highly desirable to establish a computational scheme capable of calculating hydricity in a single step. Theoretical hỵdricities in acetonitrile solution. which employs C-PCM solvent model. were reported previously. ${ }^{5}$ The accuracy of the applied computational methods was accessed by comparing the calculated Gibbs free energies of reactions involving the hydrides with the experimental data.

Recently. Creutz and Chou reported their experimental results in estimating the hydricities of $\mathrm{d}^{6}$ metal hydride complexes in water from the redox properties and acidities. or by equilibrating them with carbon dioxide/formate ion. ${ }^{3}$ An aqueous solution has been recognized as a desirable media for cataly sis and solar generation of fiels. However. only a few kinetics and equilibrium studies on hydricity in aqueous media have been reported so far.

We performed density functional theoretical (DFT) calculations on these transition metal hyddrides and correlated the results with the experimental data in an aqueous solution.

\section{Computational Details}

The calculation scheme parallels our own previously reported scheme for $\mathrm{pK}_{\mathrm{a}}$ evaluation. ${ }^{8.11}$ Summarized below are the features of the calculation relevant to the discussion of the data.

The hydricity of a molecule $\mathrm{AH}$ in aqueous solution is the Gibbs free energy of the heterolytic dissociation process (ustlally expressed in the unit of eV, $\Delta G_{(\text {liss } . k j,}^{0}$, which is defined as follows (See Schente 1):

$$
\Delta G_{\mathrm{diss} . \mathrm{aq}}^{\mathrm{a}}=\Delta G_{\mathrm{aq}}^{0}\left(\mathrm{~A}^{-}\right)+\Delta G_{\mathrm{aq}}^{0}\left(\mathrm{H}^{-}\right)-\Delta G_{\mathrm{aq}}^{0}(\mathrm{AH}) .
$$

The standard free energy of each species $\left(\mathrm{AH}, \mathrm{A}^{+}\right.$. and $\left.\mathrm{H}^{-}\right)$ in water, $\Delta G_{\mathrm{aq}}^{0}$, can be written by as the sum of the gas-phase standard free energy $\Delta G_{\mathrm{g}}^{0}$ and the standard free energy of solvation in water $\Delta G_{s o l v}^{0}$ :

$$
\Delta G_{\mathrm{aq}}^{0}=\Delta G_{\mathrm{g}}^{0}+\Delta G_{\mathrm{sol}}^{0}
$$

The standard free energy of each species in the gas phase, $\Delta G_{\mathrm{g}}^{\mathrm{l}}$. is obtained by

$$
\Delta G_{\underline{g}}^{0}=E_{0 \mathrm{~K}}+\mathrm{ZPE}+\Delta \Delta G_{0 \rightarrow 199 \mathrm{~K}} .
$$

The total energy of the molecule at $0 \mathrm{~K}\left(E_{\langle\mathrm{K}}\right)$ is calculated at the geometry optimized with quantum mechanics (QM). Harmonic oscillator-rigid rotor approximation is applied for the calculation. The zero-point energy ( $Z P E$ ) and the vibrational contribution to the Gibbs energy change from $0 \mathrm{~K}$ to $298 \mathrm{~K}$ $\left(\Delta \Delta G_{0 \rightarrow 208}\right)$ are calculated from the frequencies obtained from the QM calculations. The translational and rotational free energy contribution is also calculated in the ideal gas approximation. We take $\Delta G_{\text {aq }}^{0}\left(\mathrm{H}^{-}\right)$as a fitting parameter to ensure the best reproduction of the experimental data. as used in the previous works on $\mathrm{p} K$ il calcuations. 11,1 ?

All QM calculations used the Jaguar v5.5 quantum chemistry 


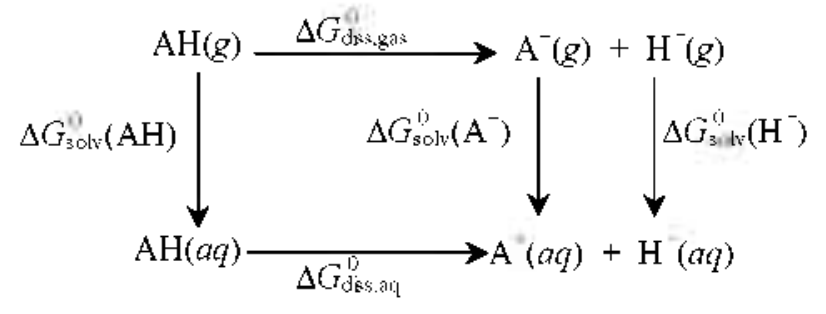

Scheme 1. Thermodynamic cycle used in the calculation of hydricity values

Table 1. Experimental and Calculated hydricities (inn eV) of hydride complexes

\begin{tabular}{|c|c|c|c|c|c|}
\hline & \multirow{2}{*}{ Hydride complex } & \multicolumn{3}{|c|}{ Hydricity } & \multirow{2}{*}{$\begin{array}{c}\Delta G_{\text {dip? gas }}^{0} \\
\text { calc }^{c^{l}}\end{array}$} \\
\hline & & expt $t^{a}$ & $\mathrm{calc}^{b}$ & fitted ${ }^{c}$ & \\
\hline 1 & $\mathrm{Co}(\mathrm{CN})_{5} \mathrm{H}^{3-}$ & 0.67 & 0.40 & 0.48 & -0.77 \\
\hline 2 & $\mathrm{Ru}(\mathrm{tpy})(\mathrm{bpy}) \mathrm{H}$ & 0.96 & 0.66 & 0.79 & 12.01 \\
\hline 3 & $\mathrm{RhCp} p^{*}(\mathrm{~b} p y) \mathrm{H}^{-}$ & $1.1 \hat{3}$ & 1.20 & 1.44 & 13.12 \\
\hline 4 & $\mathrm{Ru}\left(\mathrm{Bz}^{*}\right)(\mathrm{bpv}) \mathrm{H}^{-}$ & 1.35 & 1.15 & 1.38 & 12.98 \\
\hline 5 & $\mathrm{Co}(\text { bpy })_{2} \mathrm{H}\left(\mathrm{H}_{2} \mathrm{O}\right)^{--}$ & 1.58 & 1.59 & 1.90 & 16.53 \\
\hline 6 & $\mathrm{Rh}(\mathrm{en})_{2}\left(\mathrm{H}_{2} \mathrm{O}\right) \mathrm{H}^{2+}$ & 2.03 & 1.48 & 1.77 & 18.34 \\
\hline 7 & $\mathrm{Co}(\mathrm{HMD}) \mathrm{H}\left(\mathrm{H}_{2} \mathrm{O}\right)^{2+}$ & 2.12 & 1.75 & 2.09 & 17.24 \\
\hline 8 & $\mathrm{Rh}(\mathrm{bpy})_{\hat{\alpha}} \mathrm{H}\left(\mathrm{H}_{\hat{\alpha}} \mathrm{O}\right)^{\hat{*}-}$ & 2.19 & 1.83 & 2.19 & 16.65 \\
\hline
\end{tabular}

HMD $=5.7 .7 .12,14.14$-hexamethyl-1,4.8.11-tetraazacyclotetradeca4.11-diene. reference [1]. from the calculated results using B3L YP LACVP** with $\Delta G_{\mathrm{aq}}^{0}\left(\mathrm{H}^{-}\right)$giving best fit with a $\mathrm{H}_{2} \mathrm{O}$ molecule as a weakly bound ligand to tive-coordinated complexes. "titted with the correlation result in section 3.2. from the calculated results using B3LYP LACVP** with $\Delta G_{g a}^{n}\left(\mathrm{H}^{-}\right)$giving best fit with a $\mathrm{H}_{2} \mathrm{O}$ molecule as a weakly bound ligand to five-coordinated complexes.

software. ${ }^{13}$ To perform the geometry optimization and calculate the energies of the various molecules, we used the B3LYP ${ }^{14 \cdot 13}$ variation of DFT. which includes the generalized gradient approximation and a component of the exact Hartree-Fock exchange. Since calculations of vibration frequencies are generally quite time-consuming. the small LACVP** basis set was first used to optimize the geometry and calculate the vibration frequencies. The mumber of imaginary frequencies was monitored in order to check if the optimized structure of each chemical species corresponds to true the minimum. Then singlepoint calculations with the LACV3P++** basis set were performed to check the dependence of the results on the inclusion of the diffuse function.

The water solvent was taken into account with the PoissonBoltzmann (PB) continuum model ${ }^{18}$ at the B3LYP/LACVP** level. Details for the solvation energy calculation have been presented elsewhere. ${ }^{19}$ and so we briefly describe the overall procedure. The continuum solvent model was applied to the calculations. The solvation Gibbs free energy was given by the sum of the non-electrostatic contribution due to the creation of the solute cavity in the solvent and the electrostatic interaction between the solute and solvent. The electrostatic part of the solvation free energy was evaluated by a self-consistent formalism that cycles through the QM calculations in the solvent (a)

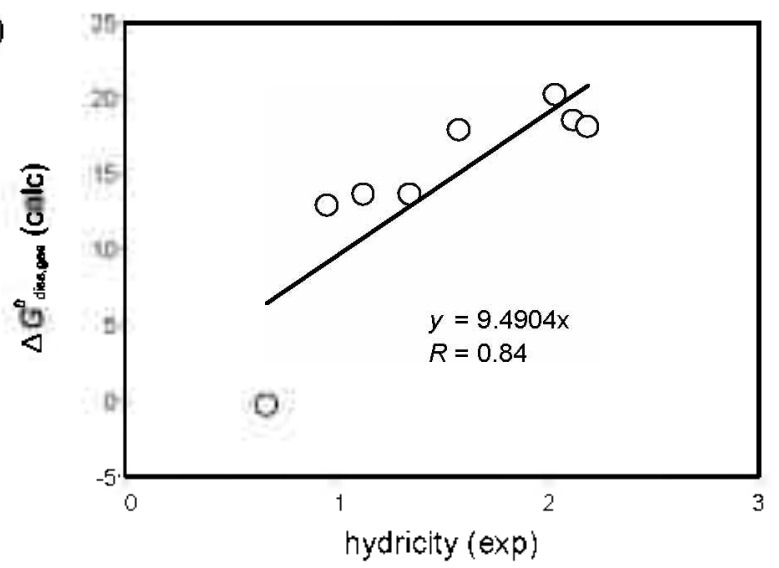

(b)

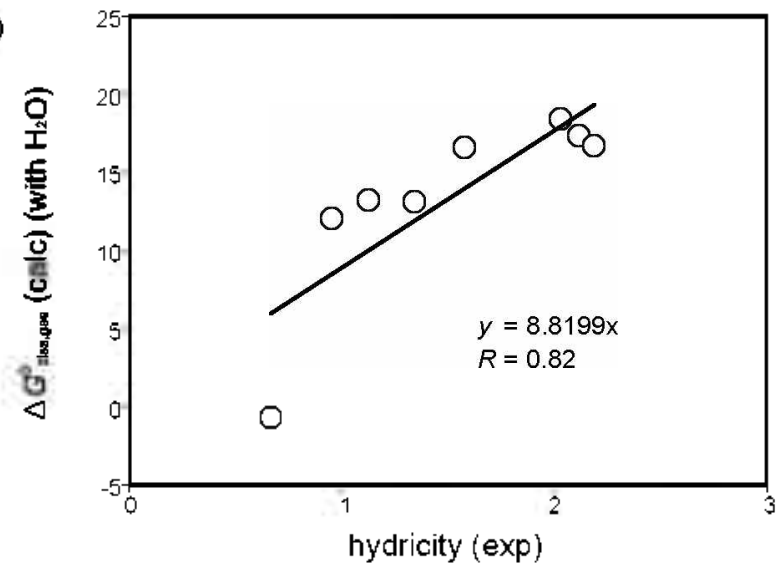

Figure 1. Gas phase hydricities of transition metal hydride complexes (a) without and (b) with a $\mathrm{H}_{2} \mathrm{O}$ molecule as a weakly bound ligand.

reaction field that involves numerical solution of the $\mathrm{PB}$ equation. ${ }^{18}$ The non-electrostatic contribution was taken into consideration by a term proportional to the solvent-accessible surface (SAS) area of the solute defined by the surface traced out by the center of the sphere of probe radius ( $1.4 \AA$ for water) as it is rolled around the solute. This term is based on the experimental solvation energy of linear and branched alkanes. ${ }^{20}$ The atomic radii to determine the van der Waals envelope of the solute were taken from Marten $e t a l .^{\text {s. }}$

\section{Results and Discussion}

Table 1 lists the chenical structures of the netal complexes used in this study and compares the calculated thermody namic quantities with the experimental estimations.

Comelation with the gas phase results. First, we correlated the hydricities of the complexes with the Gibbs energy for the dissociation of lydride in the gas phase. $\Delta G_{(b s . \text { as. }}^{\mathrm{a}}$. The Gibbs energy of hydride in the gas phase, $\Delta G_{\text {gas }}^{\prime \prime}\left(\mathrm{H}^{-}\right)$is taken as a fitting parameter chosen to ensure the best correlation. Figure I depicts the hydricities. the Gibbs energy change corresponding to the hydride dissociation reaction for the 8 molecules against the $\Delta G_{\text {drs }, \text { gas }}^{\sigma}$ values given in Table 1. The gas phase hydride dissociation energy, with $\mathrm{Co}(\mathrm{CN})_{s} \mathrm{H}^{3-}$ excluded. shows 
(a)

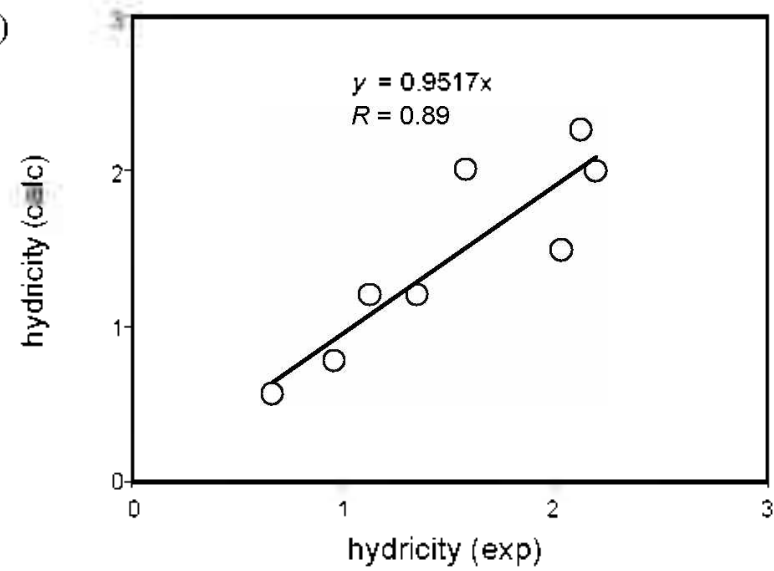

(b)

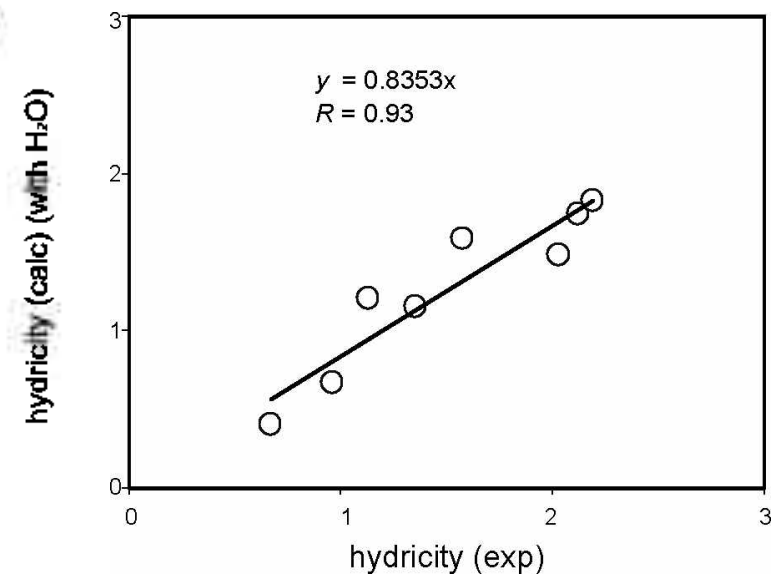

Figure 2. Hydricities of transition metal hydride complexes, (a) without and (b) with a $\mathrm{H}_{2} \mathrm{O}$ molecule as a weakly bound ligand.

good agreement with the experimental data $(R=0.90)$. However, the inclusion of the data for $\mathrm{Co}(\mathrm{CN})_{5} \mathrm{H}^{3-}$ reduces the regression coefficient to $(R=0.84)$. Taking the solvation energy' into consideration gives a much better correlation. as shown in the next section. which demonstrates that the solvation energy calculation is essential for making accurate hỵdricity evaluations. Calculations with an additional $\mathrm{H}_{2} \mathrm{O}$ molecule as a weakly bound ligand (or as a simplest model of explicit solvent model) did not improve the quality of the correlation as shown in Figure (b).

Inclusion of the single-point energy conrection with a larger set of LACV3P++** did not improve the quality of the correlation. nor did the inclusion of the geometry optimization with the LACV3P++** basis set.

Hydricities. Inclusion of the solvation energies greatly affected the results (Figure 2a). The improvement was due to the correct description of the hydricity of $\mathrm{Co}(\mathrm{CN})_{5} \mathrm{H}^{?-}(R=0.89)$. Calculations with an additional $\mathrm{H}_{2} \mathrm{O}$ molecule as a weakly binding ligand improved the quality of the correlation further. as shown in Figure 2(b) $(R=0.93)$. The scheme greatly improved the quality of the model. especially for $\mathrm{Co}(\mathrm{HMD}) \mathrm{H}\left(\mathrm{H}_{2} \mathrm{O}\right)^{3-}$. It is conjectured that the planar structure of the HMD ligand requires the inclusion of a water molecule as a weakly bound ligand. As in the gas phase thermodynamics. inclusion of a larger basis did not improve the quality of the correlation.
The net charge of the complex. the electronic structure of the metal center and the electron-donating ability of the ligand are conjectured to be related to the general trend found for the variation of the experimentally deternined hydricities. ${ }^{5.21}$ Net positive charge makes a complex less hydridic. An electronricher ligand usually makes a complex more hydridic.

\section{Summary}

In this study, we performed the B3LYP variation of DFT calculations coupled with a PB continuum solvent model to calculate the hydricity of the $\mathrm{d}^{6}$ transition metal hydrides in an aqueous solution. The conputational scheme parallels the $\mathrm{p} K_{\mathrm{c}}$ calculations. As expected. the gas phase thermodynamics results did not correlate well with the experimental hydricities. Inclusion of the solvation energy term improved the calculated hydricities to a level in good agreement with the experimental measurements. The inclusion of the diffuse function did not improve the quality of the numerical results. unlike the previous studies on the acid dissociation constants. ${ }^{8.10}$

Acknowledgments. This work was supported by the Yeungnam University Research Grants in 2007.

\section{References}

1. Creutz, C; Chou, M. H. J. An. Chem. Soc 2009, 131, 2794

2. Alajarn, M.; Bonillo, B.; Ortn, M.-M; Snchez-Andrada, P.; Vidal, A. Org. Lett. 2006, $8,5645$.

3. Mayr, H.: Lang, G.: Otial, A. R. J. Am. Chem. Soc. 2002, 12t, 4076.

4. Hayashi, H; Ogo, S.; Abura, T; Fukizumi, S. J. Am. Chent. Soc: 2003, 125,14266

5. Qi, X.-J.; Fu, Y; Liu, L.; Guo, Q.-X. Organontetallics 2007, 26, 4197.

6. Bakac. A. Dalton Trans. 2006, 1589.

7. Fu, X.; Li, S.; Wayland, B. B. Inorg. Chem. 2006, t5, 9884.

8. Hwang, S.; Jang, Y. H.; Chung, D. S. Bull. Korean Chem. Soc. $2005,26,585$.

9. Jang, Y. H.; Goddard III, W. A.: Noyes, K. T.; Sowers, L. C.; Hwang, S: Chung, D. S. Chem. Res. Toxicol. 2002, 15, 1023.

10. Jang, Y. H.; Goddard III, W. A.: Noyes, K. T:; Sowers, L. C.; Hwang, S; Chung, D. S. J. Phys. Chem. B 2003, 107, 344

11. Jang, Y. H.; Hwang, S.; Chung, D. S. Chem. Lent. 2007, $36,1496$.

12. Rogstad, K. N.: Jang, Y. H.: Sowers, L. C.: Goddard III, W. A. Chem. Res. Toxicol. 2003, 16, 1455.

13. Schrodinger. Jaguar; v 5.5; Schrodinger: Portland, OR, 1991 2003

14. Becke, A. D. Phws. Rev A $1988,38,3098$.

15. Lee, C; Yang, W: Parr, R. G. Phys Rew $B$ 1988, $37,785$.

16. Slater, J. C. The Self Consistent Field for itolecules and Solids; McGraw-Hill: New York, 1974

17. Vosko, S. H.; Wilk, L, Nusair, M. Can. J. Phws. 1980, $58,1200$.

18. Honig, B.; Nicholls, A. Science 1995, $268,1144$.

19. Marten, B.; Kim, K.; Cortis, C.; Friesner, R. A.; Murphy, R. B.; Ringnalda, M. N.; Sitkoff, D.: Honig, B. J. Phys. Chem. 1996, 100,11775

20. Tannor, D. T.: Marten, B.: Murphy, R.: Friesner, R. A.; Sitkoff, D.; Nicholls, A.; Ringnalda, M. N.; Goddard III, W. A.; Honig, B. J. Ant Chent Soc. 1994, 116, 11875.

21. Koves, G.; Ppai, I. Organometallics 2006, $25,820$. 